\title{
Education and Ethnic-Racial Relations: Altering Encounters between University and Community
}

\author{
Renata Orlandi1 ${ }^{*}$, Pamela Tais Clein Capelin², Ronaldo Aurélio Gimenes Garcia², \\ Aldo Sena de Oliveira ${ }^{1}$ \\ ${ }^{1}$ Department of Exact Sciences and Education, Blumenau Center, Federal University of Santa Catarina, Blumenau-SC, Brazil \\ ${ }^{2}$ Federal University of Southern Frontier, Campus Realeza, Paraná, Brazil \\ Email: *renata.orlandi@ufsc.br
}

How to cite this paper: Orlandi, R., Capelin, P.T.C., Garcia, R.A.G. and de Oliveira, A.S. (2018) Education and Ethnic-Racial Relations: Altering Encounters between University and Community. Open Journal of Social Sciences, 6, 76-87.

https://doi.org/10.4236/jss.2018.612008

Received: October 7, 2018

Accepted: December 15, 2018

Published: December 18, 2018

Copyright (c) 2018 by author(s) and Scientific Research Publishing Inc. This work is licensed under the Creative Commons Attribution International License (CC BY 4.0).

http://creativecommons.org/licenses/by/4.0/

\begin{abstract}
Problematizing issues involving education for ethnic-racial relations has been of great importance in the context of Brazilian education in recent years. In this article, will be presented three actions that resulted from the extension project titled Cine Debate: commented exhibitions of films and documentarie. The objective of this work is to problematize an extension project aimed at provoking debates between university and external community on ethnic-racial relations in the perspective of the relations of otherness. This project was developed at the Federal University of the Southern Frontier (UFFS) located in the city of Realeza, in the state of Paraná-Brazil, and included a series of other phenomena related to human rights enforcement/violation. Through these cultural interventions, it was possible to access and contemplate complete film, as well as clippings articulated with other activities, such as: debates open to the outside community, round tables, talk, capoeira and samba talk, musical performances and culinary tasting, provided at different times, making it possible to enhance the dialogue on the proposed themes. The actions took place on the Campus of UFFS, as well as in the house culture of another city. The dissemination of the interventions took place via radio, print and electronic media. The collaborators of the project in partnership with the community, both internal and external to the university, provoked debates with the intention of allowing reflections on plurality and deconstructing the cultural discourses that reveal a super valorization of the white culture. The subjects involved in the activities developed were provoked regarding the opportunity of re-signification of violence and privileges, since they were by various paths and misdemeanors touched by the notion of alterity. These interventions promoted supplementation in the initial training of graduates, as well as the continuing training of teachers and
\end{abstract}


citizens in general, as active individuals in the processes of affirmation of human rights.

\section{Keywords}

Ethnic-Racial Relations, Education, Human Rights

\section{Introduction}

Brazilian racial and ethnic relations are permeated by inequalities, racism, and fallacy in racial democracy. The distinctions between groups that define themselves as racially diverse and unequal usually express real relation of domination-subordination in a mystified way [1]. The contact between native Indians, black slaves, white Europeans and several other ethnic groups has diversified our cultural scene, especially with the arrival of Asians: Japanese, Syrian-Lebanese and Slavs as Ukrainians. Certainly, long-distance migrations were driven by what some authors call a migratory illusion [2].

We are part of social spaces in rich cultural diversity, in which the heterogeneity between the subjects causes strangeness, either by brand prejudice or by phenotypic racism [3]. Discriminations are unfavorable behaviors of certain subjects in relation to other members of a population, stigmatized by appearance or ethnic ancestry, the concept of race refers to social construction involving physical and cultural characteristics [4]. These racial hierarchies are manifested daily in social settings, whether by word or deed.

On the other hand, Law 10.639/03 was created, which established the obligation to teach the History of Africa and Afro-Brazilian Culture, representing progress in the deconstruction of racism. The LDBEN (Law 9.394/96) integrated the obligatory teaching of Afro-Brazilian History and Culture and of Africa into the official school curriculum. In Brazil, Law 11.645/08 amended Law 10.639/03, establishing the guidelines and bases of national education to include in the official curriculum of the educational system the obligation of Afro-Brazilian and Indigenous History and Culture.

Although there are laws governing official documents, there is a diffuse and confused presence of diversity in pedagogical practice, there being no orchestration of meaningful proposals, projects and practices [5]. In view of this, it is necessary and urgent to invest in teacher education and in the general population as critical, reflexive, attentive and engaged subjects in the social, cultural, economic and political issues of the country. The school focused on racial, cultural and social equity is a space for emancipation.

In Brazil, there are school and/or university experiences such as the Cinedebate project that adhered to Law 10.639/03, as well as Law 11.645/08 in the Pedagogical Projects, involving the university and external community in actions aimed at: The Black Movement and the Indigenous in interdisciplinary actions in commemoration of Black Consciousness Day and Indian Day. 
In the most diverse actions, the "myth of racial democracy" was approached, among others, between black and white relations criticized by Florestan Fernandes (1978) [6], about the false integration of the Negro in post-abolition society. It was not created conditions and support so that the ex-slave was fit socially and psychologically for the free work. The "brand prejudice" that is based on the depreciative view, associated to the color of the subject and other particularities, giving preference to individuals with less marked racial marks, and "prejudice of origin" exclusion and segregation in which the oppressor and the oppressed diverge and become hostile as dissimilar groups [3].

The symbolic whiteness highlighted by the elites would justify their own privileges, excluding most Brazilians from exercising their rights as full and equal citizens [7]. At this point, a project was considered with an extensionist proposal that focused on the relations of alterity in the human rights bias, thus proposing it imposes learning between whites and blacks, exchanges of knowledge, breach of distrust, joint project for the construction of a society, fair, equal, equitable [8].

It should be mentioned that the preparation and organization of the events, reported here, were carried out by the undergraduate students. Involving future Primary Education teachers in cultural activities should be part of teacher education. Regardless of the specific training of each of the courses offered at the institution provides (Letters, Chemistry, Biological Sciences and Physics) it is necessary to emphasize that the licensee will act directly with human beings with all their diversity and social conditions. Thus, understanding a little of the problems of ethnic-racial relations in the country and its consequences that directly impact on the human rights of these groups is an integral part of the training of education professionals.

Meetings focused on debate, (re)construction and awareness are hardly offered in the local and academic community, since the region where the UFFS-Realeza is located is close to the border with Argentina, far from major centers urban. It was sought in dynamic, welcoming and respectful debates, favoring the exchange of knowledge, reflections and resignifications, breaking with the fetters that bind us to excluding conceptions. In this context, the objective of this work is to problematize an extension project aimed at provoking debates between university and external community on ethnic-racial relations in the perspective of the relations of otherness.

\section{Literature Review}

Through the project intercultural, Cinedebate, encounters were opportune so that the other was seen and heard in its singularity, considering that all educational practice has as its objective to go beyond where one is [9]. The actions reported here have turned to social multiculturalism, especially in respect for human rights in the bias of ethnic-racial relations. In fact, education is not the solution to all ills, but it occupies an important place in the processes of producing 
knowledge about oneself and about others [10].

In this teaching-extension project, the dynamic and open debates permeated stereotyping, prejudices, power relations, hierarchies, racial exclusions and the whiteness phenomenon, a race systematically privileged by a historical course of colonialism and slavery. To look at social inequalities is to realize that there is a figure stereotyped by the national history that cooperates with this scenario and must be thought of. Being white requires fair skin, European features, straight hair; being white in Brazil is a social function and implies playing a role that carries within itself a certain authority or automatic respect, allowing for transit and eliminating barriers [11].

The white skin would be a tax model of subject to be idealized, followed and experienced by the afro descendant, even if it means ignoring their culture, color, hair, and other characteristics [12]. Common sense states that it is the afro descendant himself who does racism, a sense that was historically constructed by the white elite, but not considered as the fruit of it [12]. Recently, White begins to be belonging to and producing this racial conjuncture where the inequalities of opportunities and rights of the black population are directly related to the racial identity advantage of the white [13].

It is still possible to identify that being white daily produces situations of advantages over nonwhites. Different researches show that there are more facilities for access by whites [13].

To accept the cultural diversities and particularities of each race is to understand that there are no superior or inferior cultures. Each of them must be seen within what anthropologists call cultural interiority. For this reason, it can never be said that there are wild, barbaric or backward cultures. Even the oldest ones cannot be labeled in these terms. Every ethnocentric attitude must be condemned and rejected because it hurts the principle of the equal dignity of all human beings and all peoples [14].

The term "branquitude" refers to the effects in which the traits of the racial identity of the Brazilian white from the ideas about whitening [15]. It's possible compare the phenomenon of racial prejudice with an Iceberg, where the fraction that is visible to us matches the manifestations of prejudice. However, the submerged part would correspond to unmasked prejudice, a silent precursor of social exclusion [16].

Recognizing and valuing the cultural and ethnic diversity present in Brazil is indispensable for the development and overcoming of the grave and historical dilemmas of racial exclusion. Overcoming this condition means consolidating democracy by breaking with traditional models of education, embodying the values, knowledges and cultures of the various ethnic-racial groups that make up the nation. Recognition and respect for cultural diversity, as well as recognition of the plurality of identities and belongings, cannot be separated from the guarantee of democracy: that is, the guarantee of the right to participation, the full exercise of the condition of subject of law that claims and fights for new rights 
[17].

With the commitment to promote a more inclusive, democratic and participative education, a multicultural school that educates for diversity and recognizes in the other the need for a coexistence between different cultures, identities and belongings is essential. Human rights permeate all these issues, and guarantee everyone to respect for their identity and full conditions to act on their behalf. The Cinedebate in these three actions was dedicated to the problematization of ethnic-racial relations and human rights through timely meetings, in which teaching-extension activities acted to develop a culture of Human Rights in all social spaces [18]. Therefore, deep reflections on the knowledge engaged in social transformation were favored in a shared environment, re-created and articulated in favor of the emancipation of all.

\section{Methodological Paths}

In this work is reported on the promotion of three interactive movements between the academic and external community through the execution of activities in the year 2016 and 2017. The actions carried out have given rise to reflections on themes from the perspective of human rights, in the bias of ethnic-racial relations.

Each event had a unique format, proposed from the delimitation of distinct strategies, with the purpose of providing moments of encounter and sharing of experiences in welcoming and respectable debates. The exhibition of short films and documentaries were the only strategies that permeated all events during the project. The group of participants contemplated by the project, for the most part, was composed of teachers and students, both from the university and from public schools located in the city, especially young people in high school.

The development sites of the actions alternated between the house of the culture of Realeza and the Campus of the UFFS. Two of the activities turned to indigenous issues, the first of which was centered on the debate on the documentary 500 Almas. The intention of the project was to promote a depth reflection on our own history through the presentation of this documentary, which problematizes the rescue of the identity of the Guato ethnic group, which was believed to have been extinct until the 1960s, when a small but dispersed population was discovered.

On this occasion, in the house of the culture of Realeza, academic community, external and students integrants of the Kaingang tribe, students of Campus UFFS of Laranjeiras, have been sharing experiences. The proposed indigenous coffee was delineated as a didactic-pedagogical activity dedicated to the problematization of ethnic-racial relations in the indigenous perspective in the Brazilian scenario. The coffee was organized by the academics themselves, starting from are search and preparation assistance with the Kaingang indigenous students of the UFFS-Royale Nutrition Course, all of whom were under the supervision of a Nutrition Course teacher. Coffee was an opportunity for research and 
development of relations of otherness, as we feed on each other. This was a good meeting, a lesson about us, Brazilians who do not know the complexity of indigenous cultures decimated and invisible to naked eyes.

We learn from what we see, hear, smell, touch, and taste. This action provoked the learning with the other, as we nourish ourselves with the other, in this case, the Indian, meeting with the indigenous traditions that populate our food rites. The Kaingang students from an invitation, came to Realeza to participate in the evening's actions, contributing in the debate, dances and songs. The discussions were conducted by the indigenous students, highlighting the contribution of the Viviane Kellen Barão, un field education student which affirmed in one of the passages of the debate:

When I was a child, I imagined that April 19 th $^{1}$ was to be celebrated, but it's a date to remember what happened in the past and get angry. We have the invasion of the Portuguese, exploitation and violence against the indigenous people. It is a date when we should honor our companions who died in the struggle for land, defending themselves against the Portuguese invaders.

The second action of the project reported here involved the documentary Indios, the short film Pajerama e Indios no Brasil-chapter 01, both dealing with cultural diversity, indigenous miscegenation and human rights. The documentaries and the short film were used as instruments of approximation between the academic and external community. The actions were organized by students of the UFFS, Portuguese Language Undergraduate course, as well as by indigenous students of the Nutrition Course and the teachers involved in the project.

The university's teachers assisted in the actions by mediating the debate and the initial comments, opening the space for the collective discussions. This night was thus configured as an opportunity for the appropriation of indigenous customs through dialogue with the other. The actions were outlined as pedagogical activities, performed during a night dedicated to the problematization of ethnic-racial relations. To the participants of the activities, it was possible to reflect on the interfaces of education in the approach to our own history.

The actions of the night were associated with an indigenous coffee shop. The recipes were mapped through the help of these Kaingang students. The socialization of food was an opportunity to problematize the theme from the palate of the participants in an experiential didactic-pedagogical exercise, thus an opportunity for research and an approximation in the relations of otherness. We learn from what we see, hear, smell, touch and taste, socializing food is socializing experiences and culture. In this case, we seek to promote relations of alterity in the encounter between supposed whites and supposed indians, thus getting in touch with the indigenous traditions that populate our food rites, which are among the privileges of whiteness.

Concomitant with the tasting and debate, there were also pre-selected songs for the theme of the event, they were present at the reception, during the open-

\footnotetext{
${ }^{1}$ Indian day in Brazil.
} 
ing of the event and at the time of the tasting. According to Angelita Claudino, indigenous of one of the Kaingang tribes of Laranjeiras do Sul, a student of the UFFS nutrition course-Campus Realeza, music is one of the most important cultural activities for socialization in the tribes, it accompanies the dances in the ceremonies.

In both actions focused on indigenous issues there were dialogues on the importance of this culture, especially regarding approaches in school and teacher training. In the second action, the participants were seated on mats. Regarding the ornamentation of the environment, the indigenous features were exposed spontaneously, through objects that we had in our homes, such as: balaio, palm leaves, fruits, posters with illustrations inherent to indigenous culture, among others.

The third movement of the project was focused on The Black Consciousness Day, at which time a video of the music poem Gritaram-me Negra was shown, which added to other activities, such as: debates, collective reflections, samba and of capoeira. These events involved university professors, technicians, institution academics, Royal School students, and community participation in general. The dissemination was done through folders distributed in schools, in the commerce of the city, in the murals of the UFFS, dissemination in the University through the official website, with the help of Academic Centers in their respective classes and web pages, among others.

In all the opportunities of meetings with the other the debate was provoked, the greater target of the events, besides the raising of doubts about questions and themes of the different subjects proposed. The participants had the opportunity to express their ideas and opinions. There were some controversies, nevertheless at no time the discussions walked to the lack of respect or personal insults, the public always remained very attentive and willing to the dialogue and collective understanding.

\section{Results and Discussion}

Through the execution of the project Cinedebate, the subjects were able to reflect and pronounce on the existence and incessant permanence of prejudices tied to blacks, Indians and other ethnic groups. To the extent that a society that relentlessly rejects racism, as it does Brazilian society, demands spaces in which inequalities based on ethnic-racial relations can be considered [19].

In the first of the events dealing with ethnic-racial issues, culture was considered through the participation of a group of indigenous people, members of the Kaingang tribe, UFFS students from the Laranjeiras do Sul campus in Paraná. This group of students participated in the cultural interventions of the evening, as well as the debate. The event was enriched by the socialization of those present, especially of the indigenous people who reported a little of the crucial aspects that marked their cultures, beliefs, prejudices suffered and facing the daily difficulties. 
The second action focused on the Day of the Indian, in addition to the exhibits commented on, the occasion was a tasting of typical Indian foods, socialized food and experiences, since sharing food is also a way of transmitting culture. The recipes were mapped and produced by undergraduate scholarship students with the help of Kaingang students from the Nutrition course.

As Brazilians we do not know and/or deny the positive influences of indigenous and black cultures in our society, these peoples have been/are decimated throughout the centuries. In view of this, a cultural coffee was proposed as a form of socialization, allowing the problematization of the theme from the palate of the participants. This didactic-pedagogical exercise explored the senses of the participating subjects through social and cultural relations.

The reactions of the participants were a mixture of surprise to know that we have in our table the reflection of the indigenous culture and acceptance of these substantial foods that bring us closer to each other. Food and music focused on the theme were part of the event. Jean de Léry (1980) was one of the first authors to report music among indigenous peoples in Brazil, these ceremonies lasted about two hours and during that time the five hundred or six hundred savages did not stop dancing and singing in such a way, harmonious no one would say they did not know music [20].

The third movement of the project was aimed at The Black Consciousness Day made through the display of a video of the music poem Gritaram-me Negra, which brought to the surface the marks of our colonization, which excised through the process of acculturation the intrinsic characteristics the indigenous and the Negro, placing them as an archetypal figure that portrays the period of discovery and later slavery, leaving the cultural wealth of these peoples second or even third.

A samba and a capoeira wheel enriched the night. From these actions, culturally naturalized racism, social inequality and racial privileges and whiteness were problematized. All the activities made possible the collective debates, in which deep and meaningful reflections surfaced in the discussions of the proposed themes.

The debates and reflections in all actions were collective, aiming at the denaturalization of the incessant differentiation and hierarchy among the subjects, which implies the attribution of moral and intellectual inferiority to blacks and Indians, as well as privileges linked to whiteness [19]. The deconstruction of existing prejudice would be gradually overcome by the advances and transformations of class society and by the process of modernization [21]. However, the disqualification of one race in relation to another remains.

In observing literary productions in Brazil, it is considered the restrictive character of the same regarding ethnic-racial relations, since initially these productions were limited to the written text and to certain groups, the wealthiest classes, developing writings that they delighted in such circles. The initial purpose supplanted the sphere of consumption and was transferred to education, as it served to ideological formation of patriotic appreciation, in addition to con- 
tributing to a whole process of transmission of values of the ruling classes. Needs to be taken as a form of contact, a means of transmitting experiences, of other experiences of past times, emphasizing in this movement the treatment of issues of otherness, an understanding of the different contexts [21].

Vygotsky's emphasis on the dispositions that delineate the development of the human psyche, made by historical-social psychology, governs this process, is precisely a socio-historical development. Thus, the activity of language in human beings develops in a context that aggregates the interaction of several functional sectors, not only a biological, but also historical and social, contextual apparatus [22].

It is in the interaction provided by the communicational event that the subject interacts with the multiplicity of human cultural productions, producing itself historical material, insofar as its attributes meaning to the objects of the world, shares culture. It is in the meantime that the teaching of literature is characterized as a means of empowering the acquisition of knowledge about the other, about the many pluralisms, constructing possibilities for new interpretations of history, separating it from the unilateral and unilateral views of the hegemonic classes.

The implementation of the project Cinedebate elicited reflections in the intercultural dimension, following the premises of promoting an education for the recognition of the "other", for the dialogue between the different social and cultural groups, an education for the cultural negotiation [23]. The National Curricular Parameters PCN's propose that through education, citizens should be able to know and value the plurality of Brazilian socio-cultural heritage as well as socio-cultural aspects of other peoples and nations, standing against any discrimination based on cultural, class differences social, beliefs, sex, ethnicity or other individual and social characteristics [24].

The open debates sought to foster a (re)consideration of the importance of understanding the plurality of contacts and experiences arising from cultural miscegenation, characteristic of the Brazilian community. The considerations made throughout the various speeches expressed by both the teachers and the questioning students and the community in general spoke about the need to raise issues of such importance on the agenda, thinking about citizen education with a view to ethnic-racial issues and human rights.

The theme chosen for the debates focused on the formation of the subject through active participation in critical and collective reflections, making it possible to prospect for the discourse of plurality, of alterity and respect for the distinct from me. One of the roles of the school/university is to increase the cultural repertoire of citizens and open spaces that allow the transformation of education system into a place where different identities are respected and valued, considered to be enriching factors of citizenship [25].

There is a need to strengthen human rights in view of the permanence of cultural invisibility in our society. Although specifically different from class bias, 
racial or racial bias tends to coincide with it in view of the concentration of the bearers of certain racial marks on certain strata of society [3].

The school as educator and emancipator of subjects needs to intervene for the deconstruction of stigmas, otherwise, white superiority to the detriment of the indigenous and black will continue. This concern motivates the academic and external community for the collective debates and exchanges of experiences in the interrelationships between the subjects, respecting the subjectivities.

Positive actions for human rights in the general community, especially in the university community, are to offer initial and continuing teacher training, to prepare them to deal pedagogically with ethnic-racial diversity [26]. New approaches in the construction of knowledge including in the curricula and pedagogical practices the culture of the different races is to make the distinctions similar, through mutual respect and the dialogue between the identity, subjective and collective diversity of the subject.

Contributing to the process of formation of the individual is to promote intercultural encounters, to identify and prescribe intolerances and banalities in social and ethnic-racial relations, and to stimulate criticality and the active participation of individuals in the promotion of friendly and respectable interpersonal relationships. The absence of collective dialogue about racial prejudices in educational institutions and society in general will further fuel the differences between citizens, treating them in a perpendicular way.

To the racial themes addressed in the project Cinedebate established circumstantial relations of approximation between those involved in the deliberations, teachers and students turned to the cosmos of indigenous and black cultural diversity, which, even being among the hues that color the formation of our culture, seems to us so different and far away.

\section{Final Considerations}

The objectives of the project reported here were reached as community and university approached in timely meetings to speak, listen, reflect and become uneasy. The collective meetings provided access to information and exchanges of plural knowledge in the promotion of human rights, aimed at guaranteeing representativeness and social justice for minorities such as blacks and Indians. To this end, several strategies were used to systematize theory and practice around cultural and ethnic-racial issues. In any case, whatever strategies are adopted to overcome racism, prejudice and discrimination or not, they must necessarily involve the school and the university through the commitment of both.

As limitations of the work, there is no theoretical methodological deepening in anthropological and nutritional questions, since the work emphasizes expansionist strategies of relation with the community, seeking a clipping of how the native student was included in this proposal and how this inclusion may have unfolding in her life at university.

The scope of actions aimed at raising awareness of otherness relations is 
strengthened by education. However, this debate becomes unfeasible when tied to school institutions marked by successive centralizing and anti-democratic approaches, which disregard the relevance of the reflection on ethnic-racial relations, whose curricula are intentionally kept tightly closed and technicism, aligned with the interests from the market. There is an urgent need to transform the school in Brazil, including a more pluralistic curriculum, integrating different sociological, anthropological, philosophical and psychological dimensions, open and responsive to new social demands. The same goes for the didactic-pedagogical organization. Involving in the action's students of the public network, undergraduate academic training and teachers in the process of continuing training was essential, while trained citizens/trainers we cannot omit this debate that is central to the construction of a plural and democratic education in the promotion of significant learning and altering.

\section{Conflicts of Interest}

The authors declare no conflicts of interest regarding the publication of this paper.

\section{References}

[1] Ianni, O. (1972) Races and Social Classes in Brazil. Rio de Janeiro, Civilização Brasileira. "Escravidão e racismo". In: Ianni, O., Ed., Slavery and Racism, Hucitec, São Paulo.

[2] Andreazza, M.L. (1996) Paradise of Delights: Study of a Ukrainian Immigrant Group. Postgraduate Thesis, Federal University of Paraná, Curitiba, Brazil.

[3] Nogueira, O. (1998) Brand Prejudice: RaceRelations in Itapetininga. Editora Universidade de São Paulo, São Paulo.

[4] Guimarães, A.S.A. (2003) How to Work with "Race" in Sociology. Educação e Pesquisa, 29, 93-107.

[5] Kadlubitski, L. and Junqueira, S. (2010) Culture and Religious Diversity: Dialogue Needed in Search of the Universal Brotherhood. Interações, 5, 123-139.

[6] Fernandes, F. (1978) The Condition of Sociologist. Hucitec, São Paulo.

[7] Reitner, B. (2003) Racism, Democracy, and Civil Society in Brazil: Comparing Non-Governamental Organizations with Neighborhood Associations in the State of Bahia. Ph.D. Dissertation, Cuny, Brazil.

[8] Brazil. National Education Council, Brazil. Ministry of Education and Inter-American Development Bank (2004) National Curricular Guidelines for the Education of Ethnic-Racial Relations and to the Teaching of Afro-Brazilian and African History and Culture. CNE, Brasília, 151 p.

[9] Freire, P. (2007) Education as a Practice of Freedom. Paz e Terra, São Paulo.

[10] Gomes, N.L. (2012) Ethnic-Racial Diversity, Inclusion and Equity in Brazilian Education: Challenges, Policies and Practices. RBPAE, 27, 109-121.

[11] Sovik, L. (2004) Here Nobody Is White: White Hegemony in Brazil. In: Ware, V., Org. (Ribeiro, V., Trad.), Whiteness, White Identity and Multiculturalism, Garamond, Rio de Janeiro, 363-386.

[12] Silva, A.C. (2007) Bleaching and Whiteness: Basic Concepts in Training for Other- 
ness. EDUFBA, Salvador, 310 p.

[13] Schucman, L.V. (2012) Between the "Grimy" and the "White": Race, Hierarchy and Power in the Construction of the Whiteness of São Paulo. Ph.D. Thesis, Institute of Psychology, University of São Paulo, São Paulo.

[14] Oliveira, J.L.M. (2010) The Anthropological Concept of Culture. Catholic University of Brasilia, Brasília.

[15] Bento, M.A.S. (2002) Social Psychology of Racism. Vozes, Petrópolis.

[16] Carone, I. (2002) The Subjective Distance between the Classes, According to Aléxis de Tocqueville. In: Carone, I. and Bento, M.A.S., Eds., Social Psychology of Racism, Vozes, Petrópolis, 189 p.

[17] da Silva, A.T.R. (2015) Education in Human Rights: The Curriculum between Relativism and Universalism. Educação \& Sociedade, Campinas, 36, 461-478.

[18] Brasil. National Committee on Human Rights Education (2007) National Human Rights Education Plan. Special Secretariat for Human Rights/Ministry of Education/Ministry of Justice/UNESCO, Brasília.

[19] Schucman, L.V., Nunes, S.S. and Costa, E.S. (2015) The Psychology of the University of São Paulo and the Race Relations: Emerging Perspectives. Psicologia USP, São Paulo.

[20] de Léry, J. (1980) Journey to the Land of Brazil. Editora Itatiaia/EDUSP, São Paulo, Brazil.

[21] Compagnon, A. (2009) Literature for What? UFMG, Belo Horizonte.

[22] Vygotski, L.S. (2001) The Collected Works. 2nd Edition, Machado Libros, Madrid.

[23] Lopes, A.C. and Macedo, E., Orgs. (2006) Curriculum Policies in Multiple Contexts. São Paulo: Cortez, 272 p.

[24] Brasil. Secretariat of Basic Education (1998) National Curricular Parameters: Natural Sciences. MEC/SEF, Brasília.

[25] Canen, A. and Xavier, G.P.M. (2011) Continued Teacher Training for Cultural Diversity: Emphases, Silences and Perspectives. Revista Brasileira de Educação, 16.

[26] Gomes, N.L. and Silva, P.B.G. (2002) Ethnic-Cultural Experiences for Teacher Training. Autêntica, Belo Horizonte. 